\title{
Books Reviews
}

will not be comprehensive. However, in this section his references cover all the important early work and also include interesting and important data relative to the experience of prisoners of war in the hands of the Japanese twenty years ago.

The next section deals with the chemistry of thiamine and its biochemical action. Dr. Williams describes in some detail the work entailed in isolating and ultimately synthetizing thiamine. Here he is most modest in his references to the long years of hard work which he and his team endured before they achieved, in 1933, a practical method of synthesizing the vitamin. Due acknowledgment is made to the efforts of those who succeeded in isolating thiamine and those who evolved other methods than his own for its synthetization.

In Part III he gives his personal views on the practical application of the findings which have accumulated over the years in respect of this important disease. He is well known as an ardent supporter of the rice-enrichment school, and makes out a good case for his method of choice for preventing this disease, for use, at any rate, in the Philippines, the area in which his interest in the problem was first aroused in the early part of this century. The arguments are advanced clearly and with due regard to rival theories, and the possibility of other methods working at least as well, if not better, in other areas.

This book is most attractively written and commands the interest of the reader from the first page to the last. It can be warmly recommended.

C. A. BOZMAN

America's pre-Pharmacopoeial Literature. David L. Cow En. American Institute of the History of Pharmacy, Madison, Wisconsin, 1961; pp. 40; illus. fascim. \$1.00 This monograph is preceded by an interesting analysis of pharmaceutical literature in the U.S.A. by Dr. G. Sonnedecker. Professor Cowen offers a careful survey of the pharmacopoeias and dispensatories imported from Europe to be found in the institutions and private libraries of the Colonial period up to 1820 , when the first United States' Pharmacopoeia was published. There is a special chapter devoted to American publications, 1720-1820, whether veterinary, popular or of a more professional nature. The subject is thoroughly covered and shows once more the considerable benefit received in medical history by the contributions from professional historians. The importance of the outlines for the courses of chemistry prepared by Benjamin Rush is not sufficiently emphasized. In spite of their title these were the first publications printed in the U.S.A., at the turning point of the Revolution, to discuss the training of physicians in materia medica and to lay down a systematic method that was followed by every subsequent pharmaceutical text. This study gives us reason to believe that the half-century delay between the declaration of independence and the publication of the first official pharmacopoeia is an immediate reflection of the American resistance to centralized political power.

FRANGISGO GUERRA 